\title{
On the change of preferential growth orientation in chemical vapor deposition of titanium carbide by aromatic hydrocarbon precursors
}

Henrik Pedersen, Ching-Chi Lin and Lars Ojamäe

\section{Linköping University Post Print}

\section{Tweet}

N.B.: When citing this work, cite the original article.

Original Publication:

Henrik Pedersen, Ching-Chi Lin and Lars Ojamäe, On the change of preferential growth orientation in chemical vapor deposition of titanium carbide by aromatic hydrocarbon precursors, 2013, Journal of Vacuum Science \&amp; Technology. A. Vacuum, Surfaces, and Films, (31), 2.

http://dx.doi.org/10.1116/1.4792723

Copyright: American Vacuum Society http://www.avs.org/

Postprint available at: Linköping University Electronic Press

http://urn.kb.se/resolve?urn=urn:nbn:se:liu:diva-90672 


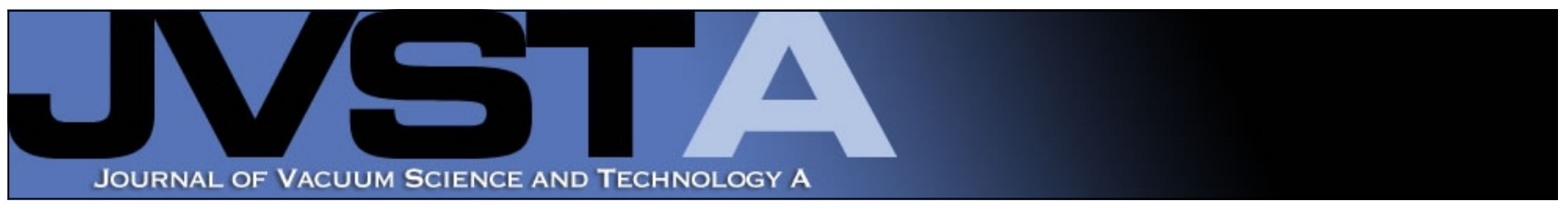

\section{On the change of preferential growth orientation in chemical vapor deposition of titanium carbide by aromatic hydrocarbon precursors}

Henrik Pedersen, Ching-Chi Lin, and Lars Ojamäe

Citation: J. Vac. Sci. Technol. A 31, 021507 (2013); doi: 10.1116/1.4792723

View online: http://dx.doi.org/10.1116/1.4792723

View Table of Contents: http://avspublications.org/resource/1/JVTAD6/v31/i2

Published by the AVS: Science \& Technology of Materials, Interfaces, and Processing

Additional information on J. Vac. Sci. Technol. A

Journal Homepage: http://avspublications.org/jvsta

Journal Information: http://avspublications.org/jvsta/about/about_the_journal

Top downloads: http://avspublications.org/jvsta/top_20_most_downloaded

Information for Authors: http://avspublications.org/jvsta/authors/information_for_contributors

\section{ADVERTISEMENT}

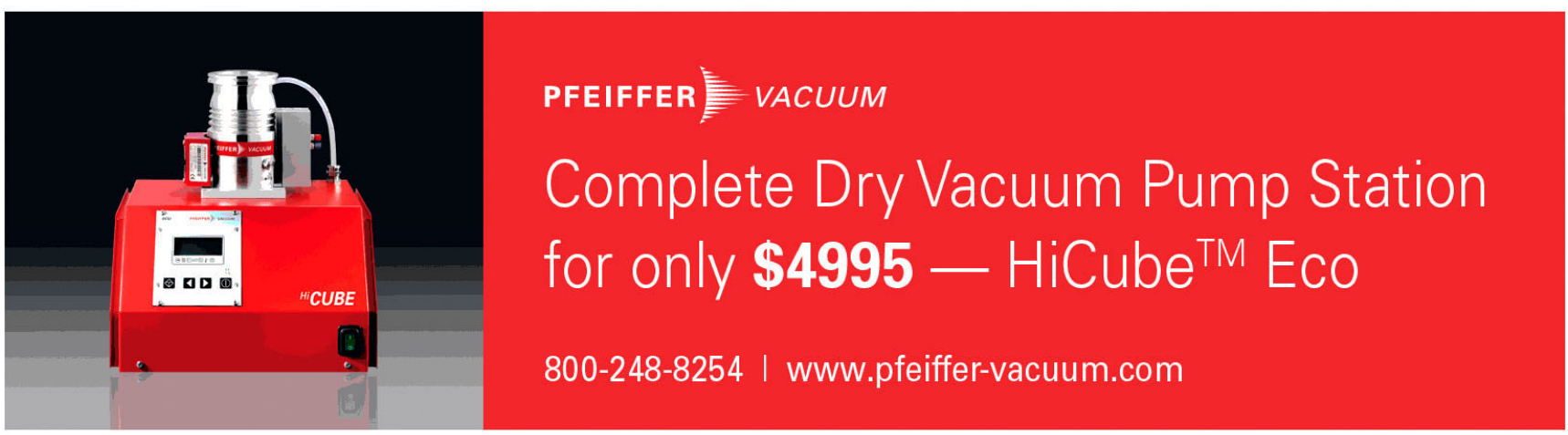




\title{
On the change of preferential growth orientation in chemical vapor deposition of titanium carbide by aromatic hydrocarbon precursors
}

\author{
Henrik Pedersen, ${ }^{a}$ Ching-Chi Lin, and Lars Ojamäe \\ Department of Physics, Chemistry and Biology, Linköping University, SE-581 83 Linköping, Sweden
}

(Received 15 November 2012; accepted 6 February 2013; published 15 February 2013)

\begin{abstract}
Thin films of titanium carbide grown by chemical vapor deposition exhibit a strong preferential (111) growth direction if aromatic hydrocarbons, such as benzene, are used as a carbon precursor. If aliphatic hydrocarbons such as methane are used, growth on the (100) surface is preferred. In this study, quantum chemical computations are used to study the adsorption of benzene and methane on the (100) and (111) surfaces to provide an explanation for the changed growth behavior. The adsorption energy of benzene is found to be approximately twice as high on the (111) surface as compared to the (100) surface, and adsorption studies further suggest that benzene chemisorbs on the (111) surface, while it physisorbs on the (100) surface. The studies reveal no significant differences in adsorption energy or behavior for methane on the two surfaces. The authors propose that the higher benzene adsorption energy and different adsorption behavior on the (111) surface are the explanations for the preferential growth orientation. (C) 2013 American Vacuum Society. [http://dx.doi.org/10.1116/1.4792723]
\end{abstract}

\section{INTRODUCTION}

Thin films of titanium carbide (TiC) have been applied as wear-resistant coatings on cutting tools since the 1960s. ${ }^{1}$ Titanium carbide is an extremely hard [Mohs 9-9.5 (Ref. 2)] refractory ceramic material that crystallizes in the NaCl-type face centered cubic (fcc) crystal structure with space group Fm-3m (No. 225). Recently, thin films of titanium carbide alloyed with other elements such as $\mathrm{Si}, \mathrm{Ag}, \mathrm{Ge}$, and $\mathrm{Al}$ have shown promising properties as electrical contact materials ${ }^{3}$ and novel low-friction coatings. ${ }^{4}$

For a long time, the method of choice for the synthesis of thin, hard, polycrystalline $\mathrm{TiC}$ films has been chemical vapor deposition (CVD). The main advantage CVD has over physical vapor deposition (PVD) is a better uniformity in the coating thickness on complex surfaces such as cutting tools because CVD is not a line-of-sight deposition technique, as is PVD. Also, CVD has approximately a $30 \mathrm{yr}$ head start on PVD in the hard coatings industry. Typically, for $\mathrm{TiC} \mathrm{CVD}$, titanium tetrachloride $\left(\mathrm{TiCl}_{4}\right)$ is used as the titanium precursor and light aliphatic hydrocarbons such as methane $\left(\mathrm{CH}_{4}\right)$ are used as the carbon precursor, with both of the precursors diluted in $\mathrm{H}_{2}$. The process temperature and pressure are about $1000^{\circ} \mathrm{C}$ and $5 \mathrm{kPa},{ }^{5}$ although singleprecursor, low-temperature CVD processes using organometallic compounds at $150{ }^{\circ} \mathrm{C}$ have been reported. ${ }^{6}$ This could be a preferred way to do TiC CVD given the lower temperature and less corrosive byproducts; however, the organometallic precursors needed for this chemistry are far more complicated and expensive to synthesize than $\mathrm{TiCl}_{4}$. The higher price and the need to alter an already functioning and optimized process makes the low-temperature process less interesting for the hard coatings industry, where CVD reactors have already been designed to handle the corrosive byproducts.

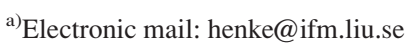

One aspect of polycrystalline films is that the crystal grains primarily grow in a random orientation, but certain process conditions or epitaxial relationships between the film and the substrate can lead to growth in a preferential orientation. The preferential growth in this study is considered to be due to competitive growth from randomly oriented nucleation. It is assumed that when growing a polycrystalline $\mathrm{TiC}$ film on a polycrystalline substrate, the nucleation is random in terms of crystal orientation and the growth will be competitive among the different facets, resulting in preferential growth on the most favorable crystal planes and a film with a preferential orientation. For hard coatings, it is often desirable to have a film with a strong preferential orientation since many material properties such as hardness varies with the crystallographic orientation. Control of the preferential growth orientation is therefore highly desired in order to optimize the performance of hard coatings. ${ }^{7}$

Leonhardt and Wolf have reported experimental observation of preferential growth orientation control of $\mathrm{TiC}$ in CVD. ${ }^{8}$ They observed that when benzene is used as the carbon precursor in CVD processes at $1050^{\circ} \mathrm{C}$, the preferential growth orientation is (111), contrasted with a preferential (100) orientation when methane is used. According to the Arrhenius plot presented in Ref. 8, both the methane and benzene processes are limited by chemical kinetics in the 950-1 $100^{\circ} \mathrm{C}$ temperature range. It should also be noted that the activation energy, which can be estimated from the slope of the Arrhenius plot, is similar for both processes. TiC films with a (111) preferential orientation were shown to perform better in cutting operations in iron $^{8}$ and can also be useful to control the preferential growth orientation of other material layers deposited on top of the $\mathrm{TiC}$ layer, such as aluminum oxide $\left(\mathrm{Al}_{2} \mathrm{O}_{3}\right) .{ }^{9}$ It has also been shown that the preferential (111) orientation for TiC films is also obtained when other aromatic hydrocarbons such as xylene and ethylbenzene are used as a carbon precursor but not when using cyclic aliphatic hydrocarbons such as cyclohexane. ${ }^{8}$ 
If we assume that the preferential growth direction of the thin polycrystalline film is not controlled or guided by epitaxial relationships from the substrate or any underlying film, the crystal orientation of the nuclei that are formed in the initial stage of film growth should be controlled by the surface energy of the various crystal facets. This would cause the grain to grow in such a way that the surface energy is minimized. It has been shown by a density functional theory generalized gradient approximation (DFT-GGA) calculation that the (100) TiC surface has a lower surface energy than the (111) TiC surface. ${ }^{10}$ This explains why a (100) preferential orientation is obtained for the "standard" TiC CVD process when a light, aliphatic hydrocarbon such as methane is used as a carbon precursor. A plausible explanation for the preferential (111) orientation obtained when using aromatic hydrocarbons is that aromatic hydrocarbons display a different behavior on the TiC surface compared to aliphatic hydrocarbons. The (111) surface of an NaCl-type fcc crystal is the only surface in the crystal that is terminated by a single atom species, which for TiC is titanium or carbon. Combined DFT and thermodynamic concepts and rate equation simulations, denoted as an "ab initio thermodynamic method for deposition growth," have shown that the (111) surface of TiC is titanium-terminated under CVD conditions $\left(1000^{\circ} \mathrm{C}\right.$ and $5 \mathrm{kPa}$ in an $\mathrm{H}_{2}-\mathrm{TiCl}_{4}-\mathrm{CH}_{4}-\mathrm{HCl}$ atmosphere). ${ }^{11}$ Given that both titanium and carbon precursors are present during the deposition process since it is not an atomic layer deposition type process and given that the $\mathrm{TiC}$ surface is found to be Ti-terminated under these process conditions, areas of the (111) surface should rapidly become titanium terminated after being covered by carbon in the growth process. Thus, the carbon chemistry can be regarded as slower than the titanium chemistry in this process.

It can further be assumed that flat, aromatic molecules with delocalized $\pi$ orbitals should be particular well suited for adsorption on the Ti-terminated (111) surface, especially since the surface is expected to be somewhat positively charged given the dipole moment in the Ti-C bonds. Such favored adsorption could explain the favored 111-texture when aromatic hydrocarbons are used as a carbon precursor. In this quantum chemical computational study, this hypothesis is explored by adsorption studies of benzene and methane on the (100) and (111) TiC surfaces. This study does not strive to present a complete chemical mechanism for the entire deposition process when using the two different carbon precursors, but instead we consider that the most crucial difference in the chemical mechanisms of the different precursors is the adsorption behavior of the carbon precursor. For the sake of this study, we will make three assumptions: (i) the desorption of the byproducts, hydrogen in both cases, should not be significantly affected by the starting molecule; (ii) the benzene molecule splits up into six $\mathrm{CH}$ on the surface given the geometry of the (111) surface, and (iii) the surface chemistry after carbon adsorption from benzene and methane is similar, given that methane renders $\mathrm{CH}_{\mathrm{x}}$ and benzene renders $\mathrm{CH}$ on the surface.

\section{COMPUTATIONAL DETAILS}

Adsorption of aromatic and aliphatic molecules on TiC was studied by quantum chemical calculations of benzene and methane on the (100) and (111) TiC surfaces. The choice of methane as the aliphatic hydrocarbon is motivated by thermochemical calculations showing that methane is the predominant carbon species in the CVD reactor when both methane and propane are used as carbon precursors. ${ }^{12}$ To facilitate the application of hybrid density functional theory computations, a cluster approach was used. In this approach, the TiC surfaces were modeled by TiC clusters cut from the optimized bulk crystal structure in order to minimize the number of unsaturated bonds and maximize the atom coordination in the clusters, similar to our previous studies. ${ }^{13,14}$ In all calculations, the (111) surface was Ti-terminated. For adsorption studies on the (100) surface, a (TiC) ${ }_{16}$ cluster containing 32 atoms in two atomic planes was used, while a $(\mathrm{TiC})_{12}$ cluster containing 24 atoms in four atomic planes was used for adsorption studies on the (111) surface. The cluster model calculations were done in the GAUSSIAN 03 molecular quantum chemistry program $^{15}$ using the hybrid density functional B3LYP (Ref. 16) and the LanL2MB basis sets. ${ }^{17-19}$ In addition, the long-range corrected CAM-B3LYP functional ${ }^{20}$ was used for reference. For comparison, calculations using a periodic model of the TiC surfaces employing a pure density functional were also performed. The periodic models consisted of slabs with a thickness of two atomic layers. The calculations were performed using density functional theory with the GGA/PW91 density functional ${ }^{21}$ and $\mathrm{DND}^{22}$ basis sets in the solid-state DMOL3 (Ref. 22) program of the MATERIALS STUDIO suite. ${ }^{23}$

The adsorption or interaction energies, $\mathrm{E}_{\mathrm{ads}}$, were calculated according to

$$
E_{\text {ads }}=E_{\text {optimized structure }}-\left(E_{\text {cluster/slab }}+E_{\text {benzene/methane }}\right),
$$

where $E_{\text {optimized structure }}$ is the energy of the adsorption complex, $E_{\text {cluster/slab }}$ is the energy of the optimized, bare crystal cluster or slab, and $E_{\text {benzene/methane }}$ is the energy of the gasphase methane or benzene molecule. A positive value of $E_{\text {ads }}$ means that the process is endothermic, while a negative value represents the exothermic reaction and implies energetically favorable adsorption.

In this study, it is assumed that the benzene molecule does not undergo any chemical reactions in the gas phase and adsorbs on the TiC surface as an intact molecule. This assumption is supported by the fact that when using benzene as a carbon precursor in plasma-enhanced CVD (PECVD) where a plasma discharge rather than thermal energy is used to activate the gas-phase chemistry, the preferential growth orientation is (100) for both aromatic and aliphatic hydrocarbon carbon precursors. ${ }^{8}$ In PECVD, the benzene molecule is expected to break down in the plasma and, since the preferential (100) orientation is obtained in a PECVD process also when using benzene as carbon precursor, the preferential (111) orientation when using benzene as carbon precursor in thermally activated CVD should thus be caused by benzene acting as an intact molecule. 


\section{RESULTS}

The surface energies of the (100) and (111) TiC surfaces were calculated from the energy difference between thin slabs of material and bulk material as the energy difference divided by the surface area. From our periodic calculations, the surface energy of the (111) surface is $0.332 \mathrm{eV} / \AA^{2}$, which is almost three times higher than the surface energy of the (100) surface $\left(0.121 \mathrm{eV} / \AA^{2}\right)$. These results agree with the lower surface energy for the (100) surface previously reported. ${ }^{10}$

\section{A. Adsorption of benzene on $\mathrm{TiC}$ (100) and (111) surfaces}

After the adsorption of benzene on (100) TiC, the distance between the benzene molecule and the surface is $3.13 \AA$ (Fig. 1) which is indicative of physisorption. Using the dispersion-corrected functional, this distance decreases slightly to $3.10 \AA$. The benzene molecule is found to expand upon adsorption on the (100) surface, expanding symmetrically so that the distance between two carbons in the benzene molecule increases from 1.40 to $1.42 \AA$.

A more reactive behavior is shown by the benzene molecule on the (111) surface, where the distance to the surface is $2.57 \AA$ (or $2.59 \AA$ using the long range-corrected functional) which indicates that the molecule chemisorbs to the surface (Fig. 2). Here, chemisorption is considered an adsorption that results in the formation of a chemical bond while physisorption is an adsorption with only van der Waals forces. Upon adsorption on the (111) surface, the benzene ring is again found to expand, although in such a way that the symmetry of the molecule is lost (see Table I). Given the short distance between the benzene and $\mathrm{TiC}$ surface and the expansion of the benzene ring to better fit the $\mathrm{TiC}$ (111) surface lattice, the benzene molecule is regarded as chemisorbed which implies an electron transfer from the electron-rich benzene ring to the electron-deficient Ti-terminated $\mathrm{TiC}$ surface. Further, the hydrogen atoms in the benzene molecule are bent upward, away from the TiC surface, upon adsorption on the (111) TiC surface. This is an indication that the hybridization of the carbon atoms in the benzene molecule changes from $\mathrm{sp}^{2}$ to $\mathrm{sp}^{3}$ upon adsorption.

Our calculations show the benzene adsorption energy on the $\mathrm{TiC}(100)$ surface $\left(\mathrm{E}_{\text {ads }}(100):-1.54 \mathrm{eV}\right)$ to be significantly lower than that on the $\mathrm{TiC}(111)$ surface $\left(\mathrm{E}_{\mathrm{ads}}(111):-2.53 \mathrm{eV}\right)$. The energies found using the dispersion-corrected functional

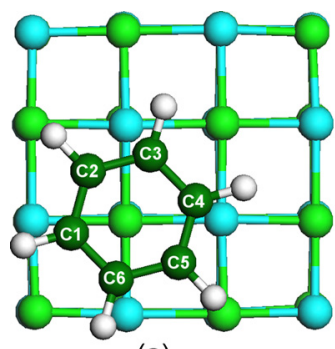

(a)

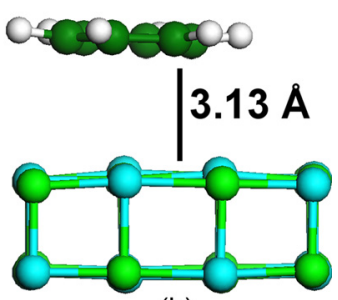

(b)
FIG. 1. (Color online) Benzene adsorption on the (100) TiC surface as calculated by the cluster model in the (a) top view and (b) side view. Lighter colored (cyan) atoms are titanium and darker colored (green) atoms are carbon.

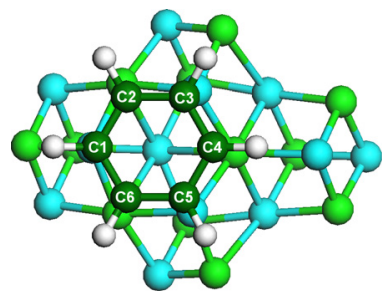

(a)

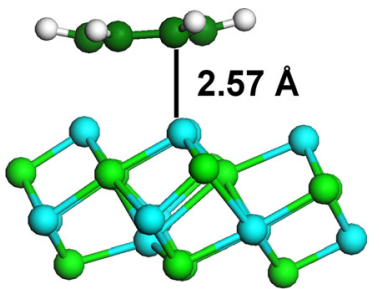

(b)
FIG. 2. (Color online) Benzene adsorption on the (111) TiC surface as calculated by the cluster model in the (a) top view and (b) side view. Lighter colored (cyan) atoms are titanium and darker colored (green) atoms are carbon.

are -1.69 and $-2.63 \mathrm{eV}$, respectively. It should also be noted that when the benzene molecule initially was placed at an angle to the surface, i.e., not parallel to the surface, it was found that the benzene always bends down and adsorbs parallel to the surface on both the (100) and (111) surfaces regardless of the initial tilt angle.

Additional studies using periodic models showed very similar results to the cluster model calculations; the distance between the benzene molecule and the (100) TiC surface is found to be $2.76 \AA$, indicating that the molecule is physisorbed, while the distance between the molecule and the (111) surface is $2.09 \AA$, indicating chemisorption. In the periodic model, the benzene ring expands only when adsorbing on the (111) surface (see Table I). Also, in the periodic model, the six-fold symmetry of the benzene molecule is lost in the expansion upon adsorption on $\mathrm{TiC}$ (111); not all of the $\mathrm{C}-\mathrm{C}$ bonds expand equally and the hydrogen atoms in the benzene molecule are bent upward away from the surface upon adsorption, indicating that the hybridization of the benzene carbons turns toward $\mathrm{sp}^{3}$. The adsorption energies calculated by the periodic model calculations are $E_{a d s}$ $(100)=-1.49 \mathrm{eV}$ and $\mathrm{E}_{\mathrm{ads}}(111)=-3.00 \mathrm{eV}$.

\section{B. Adsorption of methane on TiC (100) and (111) surfaces}

Methane adsorption on the (100) and (111) TiC surfaces was studied using the cluster model by (i) letting an intact $\mathrm{CH}_{4}$ molecule interact with the surface and (ii) placing a $\mathrm{CH}_{3}$ group and a hydrogen on the surface to study dissociative adsorption. When an intact methane molecule was introduced to the (100) TiC surface, it adsorbed on a titanium site with one $\mathrm{C}-\mathrm{H}$ bond parallel to the surface normal. The distance between the $\mathrm{C}$ molecule and the surface $\mathrm{Ti}$ was calculated to be $3.54 \AA$ and the $\mathrm{H}-\mathrm{Ti}$ distance was $2.42 \AA$ [Fig. 3(a)]. When a $\mathrm{CH}_{4}$ molecule was placed in a similar position on the (111) surface, the molecule flipped around and adsorbed with its three $\mathrm{C}-\mathrm{H}$ bonds obliquely down toward the surface with a $\mathrm{C}-\mathrm{Ti}$ distance of $2.61 \AA$, two H-Ti distances of $2.52 \AA$, and one of $2.49 \AA$. The molecule also migrates toward the edge of the cluster, as seen in Fig. 4(a). The adsorption energies calculated for an intact methane molecule are $\mathrm{E}_{\mathrm{ads}}$ (100) $=-0.18 \mathrm{eV}$ and $\mathrm{E}_{\mathrm{ads}}(111)=-0.44 \mathrm{eV}$.

Adsorption studies of the dissociated methane molecule on the $\mathrm{TiC}(100)$ surface show that heterolytic dissociation, with a positive hydrogen ion $\left(\mathrm{H}^{+}\right)$bound to a surface $\mathrm{C}$ and a methyl anion bound to a surface Ti, was preferred over 
TABLE I. C-C bond lengths and C-C-C bond angles in benzene after adsorption on the (111) TiC surface. The bond lengths are 1.40/1.39 $\AA$ using the periodic/ cluster models, and the angles are $120^{\circ}$ for benzene in the gas phase.

\begin{tabular}{lccccc}
\hline \hline Bond & Periodic model $(\AA)$ & Cluster model $(\AA)$ & Angle & Periodic model $\left(^{\circ}\right)$ & Cluster model $\left({ }^{\circ}\right)$ \\
\hline C6C5 & 1.42 & 1.44 & C4C5C6 & 118.7 & 120.3 \\
C5C4 & 1.46 & 1.44 & C3C4C5 & 17.3 & 119.6 \\
C4C3 & 1.48 & 1.43 & C4C3C2 & 119.3 & 120.7 \\
C3C2 & 1.45 & 1.43 & C3C2C1 & 120.6 & 119.1 \\
C2C1 & 1.44 & 1.43 & C2C1C6 & 120.3 & 119.8 \\
C1C6 & 1.42 & 1.43 & C1C6C5 & & \\
\hline \hline
\end{tabular}

homolytic dissociation, with a hydrogen atom bound to a surface $\mathrm{Ti}$ and the methyl group to a surface $\mathrm{Ti}$, by about $1.8 \mathrm{eV}$. The distance between the surface $\mathrm{Ti}$ and the methyl $\mathrm{C}$ was $2.11 \AA$ and the $\mathrm{H}$-surface $\mathrm{C}$ bond length was $1.14 \AA$ [Fig. 3(b)]. For the (111) surface, dissociative homolytic adsorption of the methane was preferred over heterolytic dissociation, where the methyl group adsorbs three titanium atoms with one C-Ti distance of $2.23 \AA$ and two of $2.56 \AA$, and an adsorbed $\mathrm{H}$-surface Ti distance of $2.00 \AA$ with two Ti at slightly longer distances of $2.29 \AA$ [Fig. 4(b)]. The adsorption energies calculated for a dissociated methane molecule are $\mathrm{E}_{\mathrm{ads}}(100)=+1.66 \mathrm{eV}$ and $\mathrm{E}_{\mathrm{ads}}(111)=-0.40 \mathrm{eV}$. It should be noted that the dissociative adsorption of methane on TiC (100) and (111) is not as energetically favorable as adsorption of the undissociated molecule, although the difference is slight for the (111) surface, and dissociative adsorption on (100) $\mathrm{TiC}$ is endothermic.

\section{DISCUSSION}

Our calculations indicate that the (111) TiC surface is more reactive than the (100) surface, though the (100) surface is still the dominating surface in standard CVD conditions, where $\mathrm{TiCl}_{4}$ and $\mathrm{CH}_{4}$ are used as precursors at around $1000{ }^{\circ} \mathrm{C}$ and result in polycrystalline $\mathrm{TiC}$ films grown preferentially in the (100) direction. As argued above, crystal growth primarily takes place on the crystal planes with the lowest surface energy to minimize the crystal energy, and since there is little difference in the methane adsorption energy on the (100) and (111) surfaces, the preferential (100) growth when using methane is explained by the lower

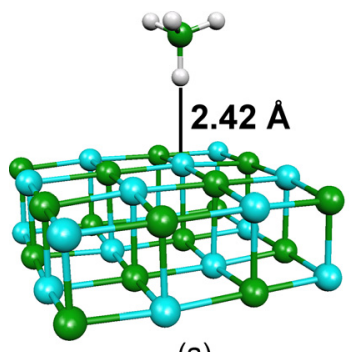

(a)

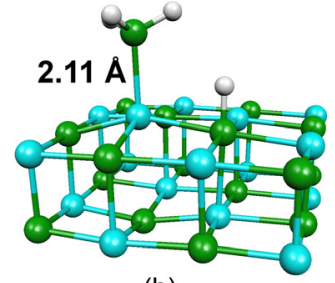

(b)
FIG. 3. (Color online) Methane adsorption on TiC surfaces as calculated by the cluster model. (a) shows the undissociated molecule adsorption on the (100) surface and (b) shows the dissociated (heterolytic) molecule adsorption on the (100) surface. Lighter colored (cyan) atoms are titanium and darker colored (green) atoms are carbon. surface energy of the (100) surface. A molecule that adsorbs very strongly on another crystal surface should then be able to change the preferential growth direction if the adsorption energy is high enough to overcome the higher surface energy of the new preferential growth surface.

As shown by the calculations presented in this paper, the benzene adsorption energy on the (111) surface compared to the (100) surface is significantly higher, which should be a driving force for the crystals to grow in the (111) direction. The calculations presented here also indicate that the benzene adsorption behavior is different for the (111) and the (100) surfaces, and the expansion and deformation of the benzene ring upon adsorption on the (111) surface indicates that it is acting as a CVD precursor and contributing to growth of the TiC film. On the (100) surface, the benzene ring is physisorbed and thus not fully active as a CVD precursor. The higher benzene adsorption energy on the (111) surface is further supported by the fact that the (111) surface is terminated by titanium atoms which are only weakly electronegative with a value of 1.54 on the Pauling scale. Since carbon has an electronegativity of 2.55 on the Pauling scale, the Ti terminated (111) surface can be regarded as positively charged, thereby making adsorption of flat molecules with large delocalized $\pi$-electron systems favorable. Meanwhile, the calculations show that there is only a very small difference in adsorption energy for an intact methane molecule on the (100) and (111) surfaces, and that dissociative adsorption of methane is less energetically favorable, which should lead to preferred growth on the (100) surface due to the lower surface energy. The experimental observations of a change in the preferential orientation should therefore
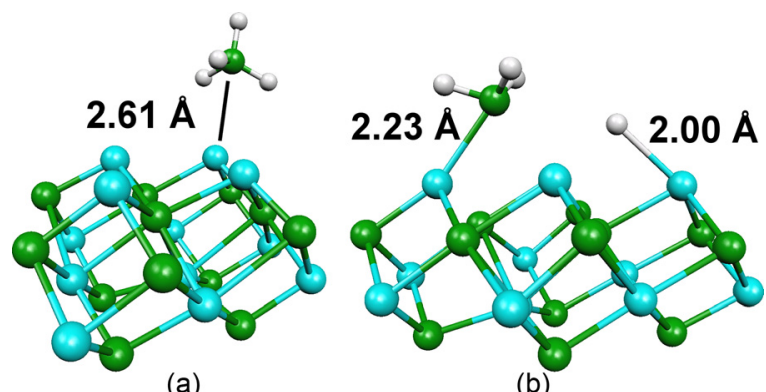

FIG. 4. (Color online) Methane adsorption on TiC surfaces as calculated by the cluster model. (a) shows the undissociated molecule adsorption on the (111) surface and (b) shows the dissociated (homolytic) molecule adsorption on the (111) surface. Lighter colored (cyan) atoms are titanium and darker colored (green) atoms are carbon. 
mean that the approximately doubled benzene adsorption energy on (111) TiC compared to (100) $\mathrm{TiC}$ is enough to overcome the higher surface energy associated with growth on the (111) surface.

\section{SUMMARY AND CONCLUSIONS}

The surface chemistry for adsorption of benzene and methane on $\mathrm{TiC}$ was studied by quantum chemical calculations to investigate the change in the preferential growth orientation of thin, polycrystalline $\mathrm{TiC}$ films grown by CVD using benzene as a carbon precursor. The benzene adsorption energy on $\mathrm{TiC}$ is approximately twice as high on the (111) surface as compared to the (100) surface. Further, the adsorption studies suggest that benzene chemisorbs on the (111) surface, while it physisorbs on the (100) surface. No significant difference in the methane adsorption behavior or energy between the (100) surface and the (111) surface is seen. We suggest that the higher benzene adsorption energy and more reactive adsorption behavior on the (111) surface explain the preferential growth on the (111) surface, while the lower surface energy of the (100) surface leads to preferential growth on the (100) surface when using methane.

\section{ACKNOWLEDGMENTS}

Financial support from the Swedish Research Council (VR) and computational resources from the Swedish
National Supercomputer Centre (NSC) are gratefully acknowledged.

${ }^{1}$ K. L. Choy, Prog. Mater. Sci. 48, 57 (2003).

${ }^{2}$ D. R. Lide, CRC Handbook of Chemistry and Physics, 85th ed. (CRC, Boca Raton, 2004-2005), pp. 12-236.

${ }^{3}$ J. Lauridsen, P. Eklund, J. Jensen, A. Furlan, A. Flink, A. M. Andersson, U. Jansson, and L. Hultman, Thin Solid Films 520, 5128 (2012).

${ }^{4}$ O. Wilhelmsson, M. Råsander, M. Carlsson, E. Lewin, B. Sanyal, U. Wiklund, O. Eriksson, and U. Jansson, Adv. Funct. Mater. 17, 1611 (2007).

${ }^{5}$ H. E. Hintermann, Thin Solid Films 84, 215 (1981).

${ }^{6}$ G. S. Girolami, J. A. Jensen, and D. M. Pollina, J. Am. Chem. Soc. 109, 1579 (1987).

${ }^{7}$ S. Ruppi, Surf. Coat. Technol. 202, 4257 (2008).

${ }^{8}$ A. Leonhardt and E. Wolf, Mater. Sci. Eng. A 209, 389 (1996).

${ }^{9}$ S. Canovic, B. Ljungberg, and M. Halvarsson, Micron 42, 808 (2011).

${ }^{10}$ A. Arya and E. A. Carter, J. Chem. Phys. 118, 8982 (2003).

${ }^{11}$ J. Roher and P. Hyldgaard, Phys. Rev. B 82, 045415 (2010).

${ }^{12}$ S. de Persis, F. Teyssandier, A. McDaniel, and M. D. Allendorf, Chem. Vap. Deposition 8, 63 (2002).

${ }^{13}$ A. Lenz, A. Pohl, L. Ojamäe, and P. Persson, Int. J. Quantum Chem. 112, 1852 (2012).

${ }^{14}$ H. Pedersen and L. Ojamäe, Nano Lett. 6, 2004 (2006).

${ }^{15}$ M. J. Frisch et al., GAUSSIAN 03, Gaussian, Inc., Wallingford, CT, 2004.

${ }^{16}$ A. D. Becke, J. Chem. Phys. 98, 5648 (1993).

${ }^{17}$ P. J. Hay and W. R. Wadt, J. Chem. Phys. 82, 270 (1985).

${ }^{18}$ W. R. Wadt and P. J. Hay, J. Chem. Phys. 82, 284 (1985).

${ }^{19}$ P. J. Hay and W. R. Wadt, J. Chem. Phys. 82, 299 (1985).

${ }^{20}$ T. Yanai, D. Tew, and N. Handy, Chem. Phys. Lett. 393, 51 (2004).

${ }^{21}$ J. P. Perdew, J. A. Chevary, S. H. Vosko, K. A. Jackson, M. R. Pederson, D. J. Singh, and C. Fiolhais, Phys. Rev. B 46, 6671 (1992).

${ }^{22}$ B. J. Delley, J. Chem. Phys. 92, 508 (1990).

${ }^{23}$ Accelrys, Inc., MS Modeling Getting Started, Manual Release 4.0, Accelrys Software, Inc., San Diego, 2006. 